\title{
Effect of Designed Nursing Guidelines on Reducing Postoperative Discomfort Among Patients Undergoing Abdominal Surgery
}

\author{
Reda Abu Elhamd Mahmoud, Mohammad Khalil Al-Amari, Amal Mohammad Ahmad \& Attyiat Hassan \\ Hussein. \\ Nursing Teacher- Technical Institute of Nursing, Qena University, Egypt. \\ Professor of General Surgery, Faculty of Medicine, Qena University, Egypt. \\ Professor of Medical-Surgical Nursing, Faculty of Nursing, Aswan University, Egypt. \\ Lecturer of Medical Surgical Nursing, Adult Nursing Department, Faculty of Nursing, Assiut University, Egypt.
}

\begin{abstract}
Patient's undergoing abdominal Surgery often experience more severe postoperative discomfort than others. Aim of the study was to : Assess of patient's needs, Design nursing guideline, Evaluate the effect of application of designed nursing guideline on reducing post-operative discomfort among Patients Undergoing Abdominal Surgery. Research design: Quasi-experimental research design was utilized in this study. Patients and Method: the study was conducted in the Surgical department in Qena hospitals, Sample of (60) adult patient. Tools three tool were used: Tool I "Patients assessment questionnaire sheet", Tool II "designed nursing guidelines", Tool III The Symptoms Assessment Scale". Results showed that: majority of both the study and control group were female, married, illiterate, and unemployed. It was concluded that: the level of knowledge \& practice of the study group patients after application of nursing guidelines was higher than control group patients. Most of the study group patients had minimal post-operative discomfort after application of nursing guidelines. It was recommended that Nurse Administrators can provide an in-service training on postoperative discomfort assessment and management to their staff. Also Nurses would be able to differentiate patients at the high risk of developing severe discomfort after abdominal surgery.
\end{abstract}

Key words: Abdominal Surgery, Post-Operative Discomfort \& Nursing Guideline.

\section{Introduction}

Abdominal surgery is a very common operative procedure. A national survey in the United States reported that operation on the digestive system is one of the three most frequent surgical procedures. Most patients experience some discomfort postoperatively. These are usually occur as the consequences of tissues damage, perioperative manipulations, and post-surgery treatments. The most common discomfort includes pain, nausea, vomiting, fatigue, anxiety, thirst, sleeplessness, elimination problems, and abdominal distension. (DeFrances et al., 2008).

Studies reported a wide variance in the prevalence of discomfort following operation, such as pain (70\%), nausea and vomiting (20\%-30\%), sleep disturbance $(89 \%)$, fatigue/tiredness $(20 \%-93 \%)$, and drowsiness (21\%-36\%). Other recognized discomfort are lack of appetite, dizziness, elimination problems, depression, headache The prevalence and intensity of discomfort vary over the time but the most severe period is the first three days after surgery. (Schulz et al., 2009). Nausea and vomiting occurs in many postoperative patients most often related to inhalation anesthesia, which may irritate the stomach lining and stimulate the vomiting center in the brain and results from an accumulation of fluid or food in the stomach before peristalsis returns. May occur as a result of abdominal distention, which follows manipulation of abdominal organs. (National Institutes of Health, 2013)

Pain is a subjective symptom in which the patient exhibits a feeling of distress. Stimulation or trauma to certain nerve endings as a result of surgery causes pain that occurs between 12 and 36 hours after surgery and usually diminishes significantly by 48 hours. (Mei et al., 2009)

Lack of sleep is also an important postoperative discomfort. The duration of sleep after surgery was significant shorter than before hospitalization. Patients suffer from sleeplessness due to pain, noise, hospital procedures, or other discomfort feelings insufficient sleep might leads to tiredness, increase in pain intensity and prolong recovery. (Worster \& Holmes, 2009)

Thirst occurs due to inhibition of secretions by preoperative medication with atropine. Fluid lost by way of perspiration, blood loss and dehydration due to preoperative fluid restriction. Constipation and gas cramps caused by manipulation of the bowel during surgery, as well as narcotic use. (Rosén \& Matensson, 2009) 
Postoperative discomfort is influenced by various factors classifying into three categories, which are physiologic, psychologic, and situational. Factors that can affect postoperative discomfort such as age, gender, size of incision, preoperative anxiety, social support and length of the operative procedure.(Nguyen, 2010)

Nursing guideline aimed at assisting patients to take care of themselves. Provides patients with the information required to understand their condition, surgery, and recovery to prevent and manage postsurgical discomfort and to decrease/reduce hospital readmission and improving knowledge of self-care. Nursing guideline covers topics related to medication management, activity performance, Breathing and Coughing exercises, nutrition, fluid intake,........ect. Nurses play very important role in reducing postoperative discomfort this can be achieved through meeting patient's needs and providing planned effective care. Patients undergoing abdominal surgery have physical, psychological, educational and social needs. ( Fredericks, 2010).

Significance of the Study

From the extensive literature review and clinical experience in Qena hospitals we observed that most patients undergoing abdominal surgery experienced many post-operative discomforts such as pain, nausea, vomiting, fatigue, anxiety, thirst, sleeplessness, elimination problems, and abdominal distension. The patients with abdominal surgery are in need for nursing care and teaching to reduce their postoperative discomfort.

\section{Aim of the Study}

The study aimed to

- Assess of patient's needs.

- Design nursing guideline.

- Evaluate the effect of application of designed nursing guideline on reducing postoperative discomfort.

\section{Patients \& Method}

\section{Research design}

Quasi-experimental research design was utilized in this study.

\section{Setting of the study}

The study was conducted in general surgical department at Qena University hospital and General Qena Hospital.

\section{Patients}

A convenience sample of (60) adult patient from both sex, their age ranged between (18-65) years who were admitted in the surgical department undergoing major abdominal surgery operation. And divided into equal two groups: study and control (30 for each).

Tools

Data collected through using the following tools:

Tool I: Patient assessment sheet.

To assess the patient's needs, knowledge and physical assessment state It was developed by the researcher after review of national and international literature. It consists of:

Part I: patient's Socio-demographic data

Included age, gender, level of education, occupation, marital status.

\section{Part II: Medical data}

included: diagnosis, name of operation, past experience of previous operation.

Part III: Assessment of the Patients knowledge regarding abdominal surgery

Assessment of patient's knowledge about, preoperative preparation, post-operative discomfort such as pain, nausea, vomiting, thirst, fatigue, anxiety, sleeplessness, abdominal distention and elimination problems.

\section{Part IV: An observational checklist sheet}

It was designed to assess patient's performance toward patients nursing care practice. It included the following items:

Breathing and coughing exercises leg and foot exercise, early ambulation.

Tool II: Designed nursing guidelines

This tool was developed by the researcher based on patients assessment needs after reviewing current national and international literature. It was formulate and introduced to the patients in the forms of sessions. The nursing guidelines booklet was revised and modified based on the medical and nursing expertise comments, it was written in Arabic simple language with illustrations and it was concerning Information about preoperative preparation, management of post-operative discomfort.

Tool III: Memorial Symptoms Assessment Scale (MSAS)

To evaluation of patients and assessment of postoperative discomfort It developed by (Lobchuk, 2003) It included 9 common post abdominal surgery symptoms pain, nausea, vomiting, fatigue, anxiety, thirst, sleeplessness, elimination problems, and abdominal distension. The frequency score ranged from 1 (rarely) to 4 (almost constantly) and the severity score ranges from 1 (slight) to 4 (very severe). Other five-item it will used to evaluate the discomfort distress, ranged from 0 (not at all) to 4 (very much). Total score for an individual discomfort was the sum score of all three dimensions, ranged from 0 to 12 . The sum score of all discomfort, ranged from 0 to 108 . 


\section{Methods \\ Technique for data collection}

A review of current and past, local and international related literature in the various aspects of the problems using books, articles, periodicals, and magazines was done. The proposed study setting was assessed for the numbers of patients hospitalized for abdominal surgery.

\section{Content validity}

It was established by panel of five expertises from the staff of medicine and nursing field to test contents and relevance, and comprehensiveness of the tools.

\section{pilot study}

The purpose of this pilot study was of 2 folds: first to ensure the clarity of designated study tools. Second, to examine the utility of the designed tools and too identity any difficulties or problems needed to be handled before applying it. Six patients in the pilot study were excluded from the actual study sample. Modification of the sheet and checklist was done to develop the final form that is most suitable.

\section{Procedures}

- All data were collected by structured interview after the approval from University and General Qena Hospitals.

- Data were collected during the period from $1 / 6$ $/ 2014$ to $1 / 12 / 2014$. At initial interview the researcher introduced herself to initiate line of communication in order to facilitate the implementation of the tools.

- The researcher divided the patients into two group control and study and interviewed with each patient individually and explained the nature and purpose of the study.

- The control group (patients who would not be expose to the designed nursing guidelines) was interviewed and assessed by using (tool 1 and tool III).

- While study group exposed to the designed nursing guidelines(tool II), preoperatively then the researcher continued to give patients the guidelines during the post-operative period until they were discharged. assessed By using (tool I) was done for all study group patients at the time of admission, and by using (tool III) was done to all study group post operatively before discharge.

- On the day one, day two, and day three after surgery, the investigator revisited patients (control \& study group) once per day to assess their discomfort by using tool (III) and to assess post-operative activity by using(tool I Part IV Observation checklist).

- Each patient in the study group obtained a copy of the designed nursing guidelines booklet.

\section{Ethical consideration}

- Research proposal approved from Ethical committee in the Faculty of Nursing.

- There was no risk for study subject during application of the research.

- The study followed common ethical principles in clinical research.

- Written consent obtained from patients or guidance that are willing to participate in the study, after explaining the nature and purpose the study.

- Confidentiality and anonymity was assured.

- Study subject have the right to refuse to participate and or withdraw from the study without any rational any time.

- Study subject privacy will be considered during collection of data.

\section{Statistical design}

Data were collected and analyzed by computer program SPSS. Data expressed as mean, standard deviation, number and percentage. Tests for significance were applied, t-test, and one way ANOVA test, T-test is used to determine significant for numeric variable. Chi-square test is used to determine significant for non-parametric variable. A probability level of 0.05 was adopted as a level of significance. 


\section{Results}

Table (1): Distribution of studied sample (both control and study groups) as regarding to their sociodemographic characteristics.

\begin{tabular}{|c|c|c|c|c|}
\hline \multirow{2}{*}{ Items } & \multicolumn{2}{|c|}{ Control $(n=30)$} & \multicolumn{2}{|c|}{ Study $(n=30)$} \\
\hline & No. & $\%$ & No. & $\%$ \\
\hline \multicolumn{5}{|l|}{$\overline{\text { Age }}$} \\
\hline Less than 20 years & 3 & 10.0 & 0 & 0.0 \\
\hline From 20 to less than 30 years & 9 & 30.0 & 11 & 36.7 \\
\hline 30 years and over & 18 & 60.0 & 19 & 63.3 \\
\hline Mean \pm SD & \multicolumn{2}{|c|}{$42.3 \pm 4.6$} & \multicolumn{2}{|c|}{$43.1 \pm 5.4$} \\
\hline \multicolumn{5}{|l|}{ Gender } \\
\hline Male & 9 & 30.0 & 7 & 23.3 \\
\hline Female & 21 & 70.0 & 23 & 76.7 \\
\hline \multicolumn{5}{|l|}{ Educational level } \\
\hline Illiterate & 12 & 40.0 & 13 & 43.3 \\
\hline Primary & 3 & 10.0 & 5 & 16.7 \\
\hline Secondary & 12 & 40.0 & 8 & 26.7 \\
\hline University education & 3 & 10.0 & 4 & 13.3 \\
\hline \multicolumn{5}{|l|}{ Marital status } \\
\hline Single & 7 & 23.3 & 5 & 16.7 \\
\hline Married & 20 & 66.7 & 22 & 73.3 \\
\hline Divorced & 1 & 3.3 & 0 & 0.0 \\
\hline Widowed & 2 & 6.7 & 3 & 10.0 \\
\hline \multicolumn{5}{|l|}{ Occupation } \\
\hline Not working & 23 & 76.7 & 24 & 80.0 \\
\hline Working & 7 & 23.3 & 6 & 20.0 \\
\hline
\end{tabular}

Table (2) Distribution of studied sample (both control and study groups) as regarding to medical data.

\begin{tabular}{|c|c|c|c|c|c|}
\hline \multirow{2}{*}{\multicolumn{2}{|c|}{ Items }} & \multicolumn{2}{|c|}{ Control $(n=30)$} & \multicolumn{2}{|c|}{ Study $(n=30)$} \\
\hline & & No. & $\%$ & No. & $\%$ \\
\hline \multicolumn{6}{|l|}{ Type of operation } \\
\hline \multicolumn{2}{|l|}{ Appendectomy } & 10 & 33.3 & 9 & 30.0 \\
\hline \multicolumn{2}{|l|}{ Cholecystectomy } & 5 & 16.7 & 13 & 43.3 \\
\hline \multicolumn{2}{|l|}{ Exploration } & 7 & 23.3 & 0 & 0.0 \\
\hline \multicolumn{2}{|l|}{ Spleenoctomy } & 2 & 6.7 & 0 & 0.0 \\
\hline \multicolumn{2}{|l|}{ Repair inguinal hernia } & 3 & 10.0 & 4 & 13.3 \\
\hline \multicolumn{2}{|l|}{ Repair umbilical hernia } & 2 & 6.7 & 4 & 13.3 \\
\hline \multicolumn{2}{|c|}{ Repair Hernia on the diaphragm } & 1 & 3.3 & 0 & 0.0 \\
\hline \multirow{2}{*}{ Previous operation } & Yes & 3 & 20.0 & 15 & 50.0 \\
\hline & $\mathrm{No}$ & 27 & 80.0 & 15 & 50.0 \\
\hline
\end{tabular}


Table (3) Distribution of Patients' knowledge (both control \& study groups) about postoperative discomfort (pre \&post) application of nursing guidelines.

\begin{tabular}{|c|c|c|c|c|c|c|c|c|c|c|c|c|}
\hline \multirow{3}{*}{ Items } & \multicolumn{4}{|c|}{$\begin{array}{c}\text { Correct answer in pre-test } \\
(\mathbf{n}=30)\end{array}$} & \multirow{3}{*}{$\begin{array}{c}P . \\
\text { value }\end{array}$} & \multicolumn{4}{|c|}{$\begin{array}{l}\text { Correct answer in post-test } \\
(\mathbf{n = 3 0 )}\end{array}$} & \multirow{3}{*}{ P. value } & \multirow{3}{*}{ P1 } & \multirow{3}{*}{ P2 } \\
\hline & \multicolumn{2}{|c|}{ Control } & \multicolumn{2}{|c|}{ Study } & & & & & & & & \\
\hline & No & $\%$ & No & $\%$ & & No & $\%$ & No & $\%$ & & & \\
\hline $\begin{array}{l}\text { - Prepare the } \\
\text { patient before the } \\
\text { operation }\end{array}$ & 7 & 23.3 & 8 & 26.7 & 0.776 & 10 & 33.3 & 28 & 93.3 & $<0.001 * *$ & 0.567 & $<0.001 * *$ \\
\hline $\begin{array}{l}\text { - Discomfort can } \\
\text { occur after the } \\
\text { operation }\end{array}$ & 6 & 20.0 & 5 & 16.7 & 0.739 & 9 & 30 & 27 & 90.0 & $<0.001 * *$ & 0.552 & $<0.001 * *$ \\
\hline $\begin{array}{l}\text { - factors help to } \\
\text { cause discomfort } \\
\text { after surgery }\end{array}$ & 11 & 36.7 & 9 & 30 & 0.584 & 14 & 46.7 & 29 & 96.7 & $<0.001 * *$ & 0.601 & $<0.001 * *$ \\
\hline $\begin{array}{l}\text { Complications of } \\
\text { postoperative } \\
\text { discomfort }\end{array}$ & 7 & 23.3 & 5 & 16.7 & 0.519 & 9 & 30 & 26 & 86.7 & $<0.001 * *$ & 0.771 & $<0.001 * *$ \\
\hline $\begin{array}{l}\text { Important of } \\
\text { postoperative } \\
\text { Exercise }\end{array}$ & 8 & 26.6 & 10 & 33.4 & 0.573 & 9 & 30 & 27 & 90.0 & $<0.001 * *$ & 0.774 & $<0.001 * *$ \\
\hline Pain & 23 & 76.6 & 21 & 70 & 0.559 & 21 & 70 & 30 & 100 & $0.001 * *$ & 0.771 & $0.001 * *$ \\
\hline $\begin{array}{l}\text { - Nausea and } \\
\text { vomiting }\end{array}$ & 22 & 73.4 & 21 & 70 & 0.774 & 19 & 63.4 & 30 & 100 & $<0.001 * *$ & 0.581 & $0.002 * *$ \\
\hline -Thirst & 17 & 56.7 & 20 & 66.7 & 0.426 & 20 & 66.7 & 26 & 86.7 & 0.067 & 0.596 & 0.125 \\
\hline - Anxiety & 19 & 63.3 & 21 & 70 & 0.584 & 21 & 70 & 29 & 96.7 & $0.006^{* * *}$ & 0.785 & $0.012 *$ \\
\hline Sleeplessness & 18 & 60 & 20 & 66.6 & 0.592 & 16 & 53.3 & 28 & 93.3 & $0.001 * *$ & 0.795 & $0.021 *$ \\
\hline - Fatigue & 24 & 80 & 21 & 70 & 0.371 & 21 & 70 & 30 & 100 & $0.001 * *$ & 0.552 & $0.002 * *$ \\
\hline $\begin{array}{l}\text { - Abdominal } \\
\text { distention }\end{array}$ & 17 & 56.7 & 19 & 63.4 & 0.598 & 21 & 70 & 25 & 83.3 & 0.222 & 0.422 & 0.143 \\
\hline -Constipation & 20 & 66.6 & 22 & 73.3 & 0.573 & 18 & 60 & 30 & 100 & $<0.001 * *$ & 0.789 & $0.005 * *$ \\
\hline $\begin{array}{l}\text { - Urinary } \\
\text { retention }\end{array}$ & 26 & 86.6 & 28 & 93.3 & 0.389 & 23 & 76.6 & 30 & 100 & $0.005 * *$ & 0.506 & 0.492 \\
\hline
\end{tabular}

Table (4): Distribution of Patients' knowledge (both control \& study groups) about postoperative discomfort (pre \&post) application of nursing guidelines.

\begin{tabular}{|c|c|c|c|c|c|c|c|c|c|c|}
\hline \multirow{3}{*}{ Knowledge } & \multicolumn{4}{|c|}{ Control } & \multirow{3}{*}{ P. value } & \multicolumn{4}{|c|}{ Study } & \multirow{3}{*}{ P. value } \\
\hline & \multicolumn{2}{|c|}{ Pre-test } & \multicolumn{2}{|c|}{ Post-test } & & \multicolumn{2}{|c|}{ Pre-test } & \multicolumn{2}{|c|}{ Post-test } & \\
\hline & No. & $\%$ & No. & $\%$ & & No. & $\%$ & No. & $\%$ & \\
\hline Good & 9 & 30.0 & 10 & 33.3 & \multirow{2}{*}{$0.781^{\mathrm{Ns}}$} & 9 & 30.0 & 28 & 93.3 & \multirow{2}{*}{$<0.001 * *$} \\
\hline Poor & 21 & 70.0 & 20 & 66.7 & & 21 & $\overline{70.0}$ & 2 & 6.7 & \\
\hline
\end{tabular}

Table (5): Distribution of Patients' practice for study groups (pre \&post) application of nursing guidelines.

\begin{tabular}{|l|c|c|c|c|}
\hline \multirow{2}{*}{} & \multicolumn{2}{|c|}{ Practice } & \\
\cline { 2 - 5 } & Pre-test & Post-test & T-test & \\
\hline Study & $54.8 \pm 14.6$ & $94.0 \pm 14.0$ & -10.63 & $<0.001^{* *}$ \\
\hline T-test & -0.313 & -10.53 & & \\
\hline p. value & 0.755 & $<0.001^{* *}$ & & \\
\hline
\end{tabular}


Table (6): Pearson correlation coefficient between socio-demographic data \& discomfort during three days.

\begin{tabular}{|l|c|}
\hline \multicolumn{1}{|c|}{ Items } & Total discomfort score \\
\hline Age & $0.44^{* *}$ \\
\hline Gender & $0.27^{*}$ \\
\hline Educational level & $0.31^{*}$ \\
\hline Marital status & 0.11 \\
\hline Occupation & 0.03 \\
\hline Knowledge & $-0.72^{* *}$ \\
\hline
\end{tabular}

Table (7): Pearson correlation coefficients between socio-demographic data and knowledge.

\begin{tabular}{|l|c|c|}
\hline \multirow{2}{*}{\multicolumn{1}{|c|}{ Items }} & \multicolumn{2}{c|}{ Knowledge score } \\
\cline { 2 - 3 } & Control & Study \\
\hline Age & $0.44^{*}$ & $0.47^{*}$ \\
\hline Gender & 0.09 & 0.11 \\
\hline Educational level & $0.68^{* *}$ & $0.74^{* *}$ \\
\hline Marital status & 0.14 & 0.08 \\
\hline Occupation & $0.33^{*}$ & $0.37^{*}$ \\
\hline
\end{tabular}

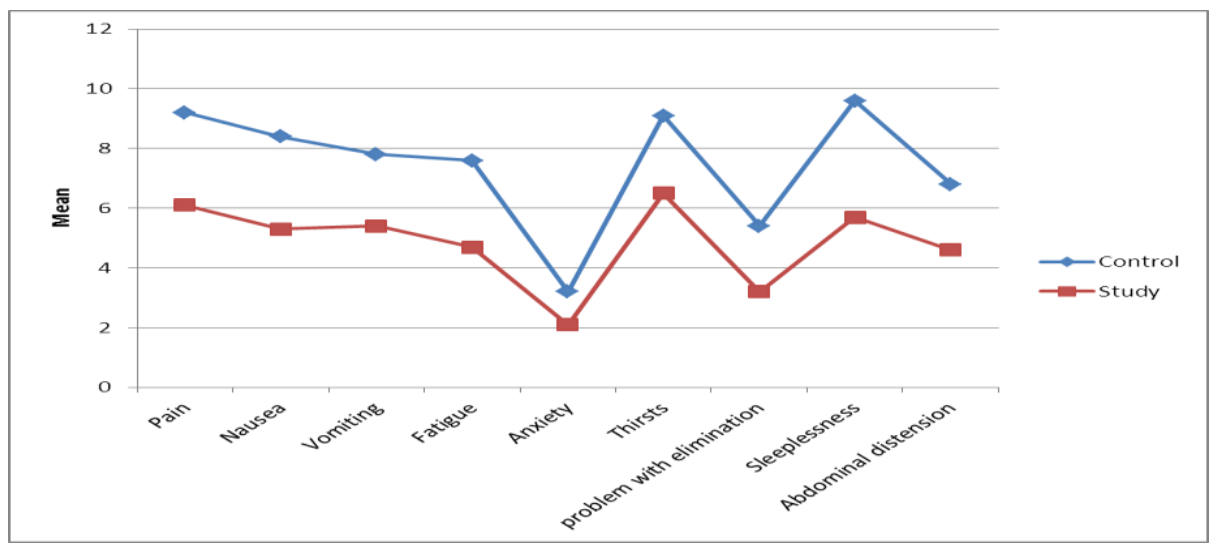

Fig: (1) Assessment of post-operative discomfort for patient's in the study and control groups for first day.

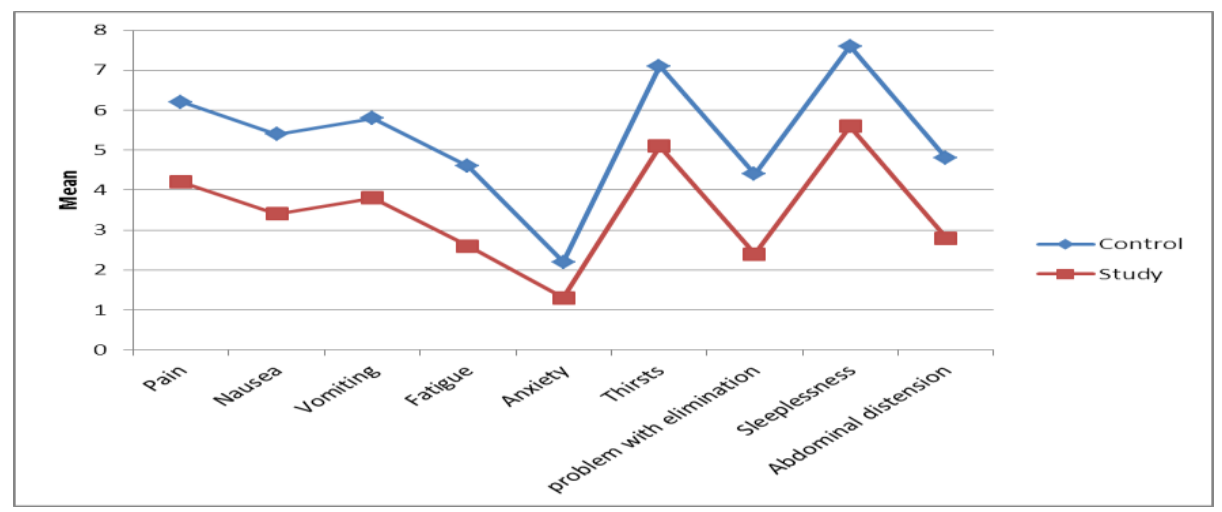

Fig (2): Assessment of post-operative discomfort for patient's in the study and control groups for second day. 


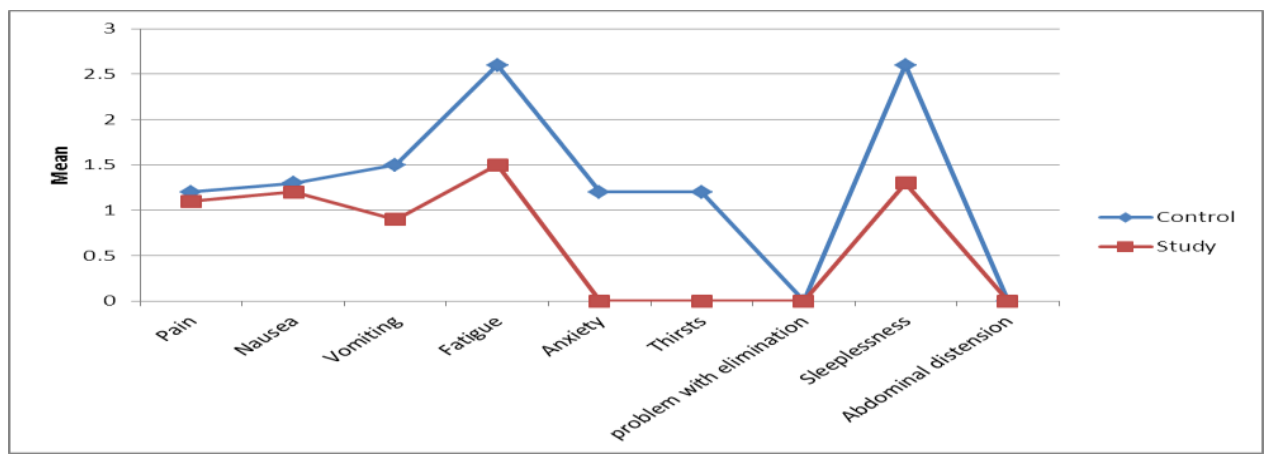

\section{Fig:(3): Assessment of post-operative discomfort for patient's in the study and control groups for third day.}

Table (1): shows that the highest percentage in both the study and control group were between the ages 30 years and over respectively. Majority of the sample in the study and the control groups were female illiterate, married, and not working.

Table (2): shows that the most common operation of control group was appendectomy (33.3\%), where the most common operation of study group was cholecystectomy $(43.3 \%)$.

Table (3): Shows that there was no statistical significant difference between pre-test and post-test regard knowledge in control group. While there was statistical significant difference between pre-test and post-test regarded knowledge in study group.

Table (4): shows that there was significant statistical difference between pre and post application of guidelines for the study group.

Table (5): shows that there was significant statistical difference between pre and post application of practice for the study group.

Table (6): This table shows strong positive correlation between discomfort and age, but negative correlation between discomfort and knowledge, mild correlation between gender and educational level.

Table (7): This table shows that there is a positive strong correlation between educational level and knowledge about discomfort in both control and study group. Where positive moderate correlation in age and occupation.

Fig (1) : significant statistical difference between study and control group in post-operative discomfort

Assessment of post-operative discomfort for patient's in the study and control groups for first day.

Fig (2): Assessment of post-operative discomfort for patient's in the study and control groups for second day.

Fig (3): Assessment of post-operative discomfort for patient's in the study and control groups for third day

\section{Discussion}

As regard to sociodemographic characteristics: The finding showed that, the highest percentage of both the study and control group were illiterate \& not working, the majority of both group was females, The age ranged between 30 and over, and more than half of them were married.

Regard to medical data: the finding showed that: the most operation of control group was appendectomy, were the most operation of study group was cholecystectomy.

As regard to patient's knowledge about, postoperative discomfort the present study showed that: statistical significant difference between pre-test and post-test in study group. These results agreed with Thomas, (2012) who carried out a study to investigate the impact of a designed nursing teaching this study found that there was highly significant between pre-knowledge and postknowledge.

In a similar study conducted by Mohamed et al., (2012) reported that, there were highly statistically significant between pre/post nursing guidelines implementation for study group.

In this regard, Abdelhameed et al., (2012) supported these result when reporting that, a higher statistically significant difference between patient's knowledge score pre and post exposure to the nursing designed protocol, and revealed that, there was significant statistical correlation between educational level and mean knowledge scores among both (control and study groups).

In agreement with this, a study conducted by Hussain and Mohamed, (2012) in the outpatient medicine clinics in Elnasr Health Insurance and Zagazig University Hospitals reported that; the implementation of the nursing guidelines program led to significant improvements in patients knowledge at the post test.

The present study showed that there was statistical significant difference between pretest and posttest for 
study group regarded practices toward patient's activity. It included the breathing and coughing exercise early amputation, leg exercise, pain control. This finding was supported by Kibler, (2012) who reported that All members of the health care team agree that consistent, early, and frequent postoperative ambulation improves both patient and provider satisfaction and has decreased postsurgical paralytic ileus, improved patient progress, and facilitated appropriate patient discharges.

As regard to post-operative discomfort The present study showed that all patients (study \&control group) complained to have pain, sleeplessness, and fatigue during three days. This finding is also in agreement with previous study Milgrom et al., (2004) who reported that all patients demonstrated pain, fatigue, and sleeplessness occurring along three days after surgery.

Mei et al., (2009) who reported that abdominal surgery is a required treatment for many body's important organs, but abdominal surgery is followed by very problematic discomfort characterized by both high prevalence and intensity.

Deglin \& Vallerand (2007) asserted the analgesic used to control pain on the first day after surgery can cause extreme fatigue.

Kehlet, (2002) which demonstrated that the impairment of nutrition status is significantly related to tirednes among abdominal surgery population.

The present study showed that there is statistical significant difference between control and study groups in day one, day two and day three. The discomfort score of study group decreased day by day along three days after surgery faster than control group, this improvement related to application of nursing guideline and improve of their knowledge to the study group.

That was agreement with previous study Hayward(2013) showed that patients who had received preoperative information required less analgesia and recovered faster than those who had not.

Fink, (2013) who reported that Patients should be knowledgeable about monitoring the development and managing postoperative discomfort are subjective experiences reflecting changes in a person's biopsychosocial function, sensation, or cognition discomfort that are commonly experienced following abdominal surgery include pain, , fatigue, nausea, vomiting, sleep disturbances, thirst, problem with elimination and mood alterations.

Moore, (1995) asserted provides patient with the information required concerned with their condition, surgery, and recovery; that improving knowledge of self-care to prevent and manage post-surgical discomfort and to decrease/reduce hospital readmission and morbidity and mortality rates.

This study revealed that the patients of control group reported high score and gradual decrease of postoperative discomfort, due to lack of knowledge.

Taylor and Stanbury, (2009) described that the lack of knowledge from both patients and healthcare workers is one of the main barrier to an effective pain management.

The study finding none of participants in study group reported abdominal distension, thirst, anxiety and elimination problem on the day three after surgery. This result supported by Rosén et al., (2009) reported The daily reduction of discomfort demonstrated that postoperative recovery was improving.

Smeltzer, (2008). which demonstrated that The absence of abdominal distension on day three reflects a good recovery of gastrointestinal function.

As Regard relationship between discomfort and sociodemographic (age, gender and educational level) the result of this study showing following: This result show Positive relation between age, gender and educational level and discomfort in this study. This finding in an Agreement with Fredericks, (2010). Age reflects the person's state of development whereby older persons have higher levels of development and are more have experience; they tend to rely on their experience to guide self-care behaviors.

The present study showed that Females in both group more experience post-operative discomfort than male This in an Agreement with Fredericks et al (2010) . Reported that gender differences in self-care knowledge, self-care behavior, and discomfort experience are well recognized. Women tend to engage in self-care more than men and to report higher levels of discomfort severity, particularly pain, mood alterations, and sleep disturbance .

The present study showed that there is a positive strong correlation between educational level and knowledge about discomfort in both control and study group. Where positive moderate correlation in age and occupation. The study conducted by Mohamed et al., (2012) is an contrary to the present study there were no correlation between patients' level of education and their level of knowledge.

Finally, it can be concluded that, the designed nursing guidelines for patients has achieved its objectives by improving patients' knowledge \& practice. That has a large role to minimize postoperative discomfort.

\section{Conclusions}

In the this study finding the level of knowledge and practice of the study group patients after application 
of nursing guidelines was higher than the level of knowledge of control group patients who didn't receive the nursing guidelines.

The most aggressive period of discomfort occurrence is the first three days after operation. Discomfort score of study group decreased day by day along three days after surgery faster than control group , result in effect of guideline which improve their knowledge In addition, same discomfort disappear on the day three after surgery in study group.

\section{Recommendations}

- Establishment of continuous health education program at surgical department to provide health teaching using booklet and illustrated pamphlets for each patient in all hospitals.

- The first day was the hardest day to patients in the present study, characterized by a highest discomfort scores. Thus, proper nursing care on the first postoperative day is essential

- Nurse administrators can provide an in-service training on postoperative discomfort assessment and management to their staff. Also, provisions of the refreshment courses should be set regularly to all staff nurses who are taking care of postoperative patients. In addition, nurse administrators should encourage their staff to join the conference related to postoperative discomfort management and postoperative care in abdominal surgery.

- Nurses would be able to differentiate patients at the high risk of developing severe discomfort after surgery. From that, nurses could prioritize interventions in order to prevent and relieve effectively postoperative discomfort.

- Replication of the study on a larger probability sample acquired from different geographical areas in Egypt to figure out the main aspects of this problems.

\section{References}

1. DeFrances, C., Lucas, C., Buie, V., \& Golosinskiy, A., (2008): National Hospital Discharge Survey. National Health Statistic Report, Center for Disease Control (CDC).

2. Schulz, P., Zimmerman, L., Pozehl, B., Barnason, S., \& Nuveen, J., (2009): Symptom management strategies used by elderly patients after coronary artery bypass surgery. Applied Nursing Research. Retrieved January 1, 2010 from Science Direct database.

3. National Institutes of Health (2013): Abdominal surgery, pain and anxiety: preoperative nursing intervention.
4. Mei, W., Seeling, M., Franck, M., Radtke, F., Brantner, B., Wernecke, K., et al., (2009): Independent risk factors for postoperative pain in need for intervention early after awakening from general anaesthesia. European Journal of Pain, Retrieved August 4, 2009 from Science Direct database.

5. Worster, B., \& Holmes, S., (2009): A., phenomenological study of the postoperative experiences of patients undergoing surgery for colorectal cancer. European Journal of Oncology Nursing, 13, 315-322

6. Rosén, H., Clabo, L., \& Matensson, L., (2009): Symptoms following day surgery: A review of the literature. Journal of Advanced Perioperative Care, 4(1),7-18.

7. Nguyen, H., (2010): Factor related to postoperative symptom among patients undergoing abdominal surgery. at internet available http://digital_collect.lib.buu.ac.th/dcms/files/519 13163/title.pdf

8. Fredericks (2010): Postoperative Patient Education: A Systematic Review at internet available

http://cnr.sagepub.com/content/19/2/144.full.pdf +html

9. Lobchuk, M., (2003): The Memorial Symptom Assessment Scale: Modified for use in understanding family caregivers' perceptions of cancer patients' symptom experiences. Journal of Pain and Symptom Management. 26(1), 644654.

10. Thomas S., (2012): A study to Evaluate the Effectiveness of the structured teaching program me on Cataract and Eye care, in terms of knowledge and practice among patients those have undergoing cataract Surgery in Retina Institute of Karnataka, Bengaluru, Indian Streams Research Journal, Vol.2,P.10

11. Mohamed H., frahat N., Meegalla N., \& Abd Elhaleem M., (2012): Nursing Guidelines on Hair Dondruff Symptoms for adult patients .life Scienco Journal 2014 Vol .11,No.1,P .323.333

12. Abdelhameed M., Mohamed W., Selomay Abd-Elsalam \& Zeghla H., El-sayed, (2012): impact of a Designed Nursing Intervention protocol on Myocardian Infarction patients Qutcome at a Selected University Hospital in Egypt.Journal of Biology,Agriculture and Health care,Vol 3, No 17,P 25:35

13. Hussan Z., Mohamed, N., (2014): Effect of nursing guideline for recently diagnosed hypertensive patient on expected clinical out comes,Journal of Nursing Education and practice, Vol.5,No.3,P:11 
14. A.Kibler, A., (2012): quality improvement project increases postoperative ambulation and decreases patient complications. Vol.112,No.4 At internet available http://unmhospitalist.pbworks.com

15. Milgrom, L., Brooks, J., Qi, R., Bunnell, K., Wuestefeld, S., \& Beckman, D., (2004): Pain levels experienced with activities after cardiac surgery. American Journal of Critical Care, 13, 116-125.

16. Mei, W., Seeling, M., Franck, M., Radtke, F., Brantner, B., Wernecke, K., et al., (2009): Independent risk factors for postoperative pain in need for intervention early after awakening from general anaesthesia. European Journal of Pain

17. Deglin, J., \& Vallerand, A., (2007): Davis's drug guide for nurses. Phyladelphia: F.ADavis Company. Kehlet, H., \& Wilmore, D., (2002). Multimodal strategies to improve surgical outcome. The American Journal of Surgery, 183, 630-641.

18. Kehlet, H., \& Wilmore, D., (2002): Multimodal strategies to improve surgical outcome. The American Journal of Surgery, 183, 630-641.

19. Hayward J., (2013): Information - A Prescription Against Pain. London: Royal Collegeof Nursing. Series 2, Number 5; 2013

20. Fink, C., (2013): Impact of preoperative patient education on prevention of postoperative complications after major visceral surgery internet available http://www.trialsjournal.com/content/14/1/271

21. Moore, S., (1995): A., comparison of women's and men's symptoms during home recoveryafter coronary artery bypass surgery. Heart \& Lung, 24(6), 495-501

22. Taylor, A., \& Stanbury, L., (2009): A review of postoperative pain management and the challenges. Current Anaesthesia \& Critical Care, 20, 188-194.

23. Smeltzer, S., Bare, B., Hinkle, J., \& Cheever, K., (2008): Brunner \& Suddarth's textbook of medical-surgical nursing (11th ed.). Philadelphia: Lippincott Williams \& Wilkins. 